Accepted for publication in The Routledge Handbook of Language and Superdiversity, ed. by Angela Creese and Adrian Blackledge, Abingdon: Routledge, 2018

\title{
Reflecting on the ethics of researching communication in superdiverse contexts Fiona Copland INTRODUCTION
}

Ethics as both epistemology and practice has been growing in importance in the social sciences at the same time as institutions have been tightening their requirements in terms of ethical approval processes. Many of our understandings about ethical research derive directly from medical models (Copland and Creese 2015) and these have been helpful in supporting social science researchers in developing ethical approaches to their work. Notwithstanding, many institutional ethics approval processes, are not a good 'fit' for the kind of work social sciences researchers do, and ethics committees can struggle to understand and then approve research designs that are embryonic or field work that is situated in sites where ethical issues cannot always be predicted. In addition, the focus on the ethics approval form as product may lull researchers into believing that ethics are not part of the research process, and therefore they do not pay attention when 'ethically important moments' (Guillemin and Gillam 2004) occur in the field.

Recently, the emergence of superdiversity as a focus of research has added a new level of complexity to considerations of being ethical. Peoples from different cultural and heritage backgrounds do not always share understandings of ethics or believe that social science research should be concerned with ethics to the same degree as invasive research, such as medicine. In these contexts, ethical issues can be sites of disagreement or contestation as different groups struggle to understand either the exact nature of the issue or why the issue has been identified as problematic. 
After introducing an historical perspective on ethics in social science research, this chapter will examine the ethical principles that researchers should consider both when planning their research projects and during the research process. It will then go on to reflect on the ethical decisions made by two researchers working in superdiverse contexts. Focusing on 'ethically important moments' (Guillemin and Gillam 2004:62) in researching communication, it will explore the ethical issues at play and how researchers resolved ethical dilemmas. The chapter will conclude by providing some useful readings for those wishing to develop their understanding of ethics in communication more fully.

\section{HISTORICAL PERSPECTIVES}

The requirement for researchers in the social sciences to seek and gain ethical approval for their studies is a relatively recent phenomenon. Although processes for seeking ethical approval have long been with us, enforcement until the turn of the century, was relatively lax. This can be seen in the number of publications from the 1970s, 80 s and 90 s where no mention of either gaining ethical approval or ethical issues is mentioned. Indeed, a number of these studies also demonstrate that ethical principles (see below) were not well understood: it is difficult to imagine how a proposal for a covert study of men having sex in toilets (Humphreys1970) would be approved today, yet this is one of the most famous ethnographies of the 1970s. In another study from the 70s, Scheper-Hughes set out to investigate sexuality in rural Ireland yet changed her focus to mental illness after an unscheduled meeting with a psychiatrist during her search for a site (Scheper-Hughes 2000). Today such a shift would be unimaginable without revisiting the ethics approval process and demonstrating due concern for vulnerable adults. Interestingly, the ethical issues raised by both publications have been much debated in recent years (e.g. Scheper-Hughes 2000).

Nowadays it is unlikely that a study on humans could go ahead in an academic institution without some form of ethical approval, usually given via a formal process that requires the 
researcher to complete some kind of form. In some institutions for undergraduate, MA and PhD study, the student's supervisor will be required to give the approval. At others, $\mathrm{PhD}$ studies may need to be considered by a panel of academics. Whatever the case, it is likely that the ethical approval officers will pose questions, ask for explanations and changes, and occasionally may refuse to sanction the research design. In this chapter I will argue that formal ethical review is important, as it provides an opportunity for researchers carefully plan their research from an ethical perspective. However, completing the forms and gaining approval is only the start: working ethically should be a constant consideration in any research that involves human participants.

\section{CORE ISSUES AND TOPICS}

At its simplest, research ethics is about what is right and wrong in the research process, contingent on the context. This may appear a fairly clear-cut definition but in reality, deciding what is right and wrong can be difficult and is a matter of judgment rather than of following a formula. Furthermore, what seems right in one context can seem wrong in another, either because of the cultural norms of the research site or the relationships that develop between researcher and researched or because the researcher develops different understandings about how research can affect people. Indeed, two researchers faced with the same ethical issue might respond quite differently to it.

In the social sciences and humanities, principles of ethical research have been drawn from medical sciences and experimental research. The first of these principles is autonomy: the participant has the right to refuse to take part. In terms of practical ethics, this principle means that participants must provide informed consent before taking part in the study. Asking for consent when researching communication can be problematic as researchers may not always know the exact focus of their research when they start, making it difficult to explain clearly to participants what the research is about. In other studies, the focus might be clear but informing 
the participants of the focus might result in their changing their behaviour, thus invalidating the findings to some extent (this was the argument made by Humphreys in his study; it is often called the 'observer effect' (Lecompt and Goetz 1982)). There is also the issue of what constitutes 'consent': should participants have to sign a consent form or is verbal consent sufficient. Signing one's name has emerged as a particular concern in superdiverse settings, which are also often cross-cultural (see below) as it carries greater import in some contexts than in others.

The principle of informed consent also means that participants have the right to withdraw from the study whenever they wish. Most researchers tell participants of this right at the beginning of their studies but may forget to remind participants of this right as the study progresses. This can mean that participants either forget about the right or find it awkward to approach the researcher during the project to broach the subject of withdrawing. Even when participants are frequently reminded of their right to withdraw, some find it difficult to do so. Kubanyiova (2010) describes how she had to gently counsel a participant off a project when she realised that being involved was causing the participant undue stress. This took both tact and persistence as the participant was loathe to let the researcher down, despite the deterimental effect being involved was having on her health.

Confidentiality and anonymity are also part of consent (and of non-malifecence - see below). Confidentiality 'concerns the treatment of information gained about individuals in the course of the research' (Davies 2008: 59). Research participants can expect that this information will not be made public without their permission. Anonymity is closely involved with consent: it is the convention that names of participants are not used so that they cannot be identified. Of course, omitting or changing a participant's name will not necessarily guarantee anonymity: they can be recognised in other ways (e.g. by linguistic expression or through contexual information). Anonymity can be difficult to preserve when visual recordings are made. Some 
argue that it is not necessary in certain kinds of research (such as participatory). Others believe that visual research requires the reader to engage with participants in a more reflexive and demanding way than written accounts allow therefore reducing the need for anonymity (see Rose 2013 or Wiles et al. 2008, for a full discussion). Nevertheless, recent advances in technology have been helpful in providing the means to anonymisation for those who require or desire it. For example, a pixelating software can obscure faces (for example, http://www.yowussup.com/pixelatingimages.php).

In some cases, participants do not wish to anoymised and encourage the researcher to use their real names. However, in most cases it is wise to counsel against this. Most research participants have very little idea of the criticality that exists in research and how quickly readers judge both participants and researchers. Furthermore, as Wiles et al. (2008) explain, 'research participants have limited understanding of the research process and the ways in which research is presented and disseminated. Even with detailed discussion about this on the part of researchers, participants are unlikely to fully comprehend the 'taken for granted' aspects of research practice' (p.34). While Wiles et al. (2008) counsel against behaving paternalistically with participants, it is also true that researchers have a duty to protect their informants. In many superdiverse settings this is particularly resonant as participants may be naïve about the potential damage or discomfort naming could cause (although see Scheper-Hughes's (2001) robust defence of her decision to both name participants and share photographs of them in the reissue of Saints, scholars and schizophrenics).

A recent paper by Vainio (2012) provides another set of strong reasons for preserving anonymity. The author suggests that anoymity serves three addition funtions in research: 'anonymity as "ontology", anonymity as "analysis" and anonymity as "independence"” (p. 685). She explains: 
First, ontologically, anonymity is a way of turning into 'data' what someone has said or written. Second, anonymisation as 'analysis' turns the participants into examples of specific theoretical categories, and as such is a part of the data analysis. Third, anonymity as 'independence' enables the researcher to interpret the data irrespective of the participants' wishes. (p. 685)

These reasons can be useful tools for persuading participants not to have their real names published.

The second principle of ethical behaviour is beneficence: the researcher should ensure the research is in the interest of the participants. Beneficence can also be difficult to achieve. One reason is because research is often characterised as 'research on' rather than 'research with' participants. The focus, therefore, is on short-term benefits for researchers through publications or qualifications, rather than on long-term benefits for those being researched through improvements to their lives. The recent emphasis placed by research councils and others on impact goes some way towards recognising that beneficence should be a motivating feature of research. Nevertheless, in the drive to get a research project off the ground or completed, it can be difficult to focus sufficiently on the needs of the research participants.

A complementary concept - non-maleficence - means that the researcher should do no harm. In the medical context from which the principle derived, harm refered to physical harm so that medical scientists were prevented from leaving people in a worse state after an experiment than before it. However, non-maleficence is also highly pertinent for qualitative researchers, although also highly problematic. In our case we must consider what to do with research findings that present participants and institutions in a way that could cause (psychological) harm. For example, what should we do with data which suggest that a participant's behaviour is unprofessional? Ensuring anonymity of participants and institutions through pseudonyms 
and other devices such as disguising features on visual images might address the concern to some extent. However, in the end the researcher must weigh up potential 'harm' against the value of the research with its potential for improving the lives of others not immediately involved in the research (see Murphy and Dingwall 2001) and make a decision. ScheperHughes (2000) provides an explanation of why exposing the mores of an Irish village was in the end beneficial in terms of understanding illness and changing behaviour.

The principle of justice ensures that everyone is treated fairly and equally (Murphy and Dingwall 2001). In research on communication in super-diverse settings, this will mean that particular positions, particularly those of the powerful (often held by European academics) are not privileged above others, particularly those of the weak or disenfranchised (who may be the field researchers).

Research in the social sciences has no doubt benefitted greatly from medical ethics and the principles it has created for the examination of ethical issues. However, the consideration of ethical issues from a medical perspective has not been without problems for qualitative work. It is to these issues I now turn.

\section{NEW DEBATES}

Although few would argue with the underlying principles of conducting ethical research as outlined above, there has been strong criticism of how universities ensure compliance. An area recently criticised is the formal ethical approval process. Generally, this starts with the researcher submitting a form to the institution's research ethics committee. As conducting ethical research has become increasingly important, the forms have grown in importance and often in complexity, making them challenging to complete effectively. After the form is submitted, a board of academics examines it. An issue that arises at this stage is that frequently these reviewers are not experts in the research norms of different research methodologies presented to them and so can impose difficult or unattainable conditions on the research project. Guta, Nixon and Wilson (2013) argue that qualitative research in particular is 
negatively affected by the ethics review process because the interpretive nature of qualitative research is not easily incorporated into the standardized protocols required by ethic review bodies. Whether because of lack or understanding on the part of the committee, or because of lack of detail provided by the researcher(s), forms are often returned a may be resubmitted a number of times before approval is finally gained.

A result of regularisation of ethics is that in higher education 'trustworthiness' becomes associated with "standardization, competence, continuity and reliability" (Morley 2003, pp. 56) so that successful form-filling - a discernable 'product' of the ethics review process - may be considered more important than the content of what is written or the way in which the research is carried out. There are two problems with this. First, researchers may come to believe that once the forms are completed and approval granted ethical concerns have been dealt with (Kubanyiova calls this area of ethical work 'macro ethics' (2008:xx)). Second, researchers may forget that working ethically is a process that requires the researcher to keep a vigilant eye open for situations in the field that might require ethical consideration (what Kubanyiova calls 'micro ethics' (2008:xx). A focus on macroethics, therefore, can distract a researcher from what is really important - behaving ethically in the field.

In many cases, it is impossible to predict all the ethical issues that might arise when conducting qualitative research, a seeming demand of the ethical review process. This is particularly the case when working in superdiverse contexts as local understandings of behaving ethically might differ substantially from those of the researcher and of the institution. In these cases, it is even more important for researchers to be sensitive to how their research behaviour might be negatively affecting participants and for them to consider on a regular basis if their research is ethically compromising.

One way to approach working in the field, and particularly in a superdiverse one, is to develop what Kubanyiova calls 'virtue ethics' and 'the ethics of care' (Kubanyiova 2008, drawing on Haverkamp 2005). Virtue ethics is the ability to recognise situations which require an ethical response and ethics of care is the ability to recognise that research is carried out in relation to people and contexts and therefore is contingent and situated. Researchers should, therefore, be sensitive to recognising 'ethically important moments' (Guilleman and Gillam 2004) that is 'the difficult, often subtle, and usually unpredictable situations that arise in the practice of doing research.' (p.62). The following sections will explore ethically important moments in researching communication in two superdiverse settings and how the researchers dealt with the 
moments with consideration of virtue ethics and ethics of care. However, before beginning this discussion, I describe my understanding of superdiversity.

\section{Superdiversity}

As readers of the volume will be aware, the term superdiversity was first introduced by Vertovec (2007) to describe the increasing spread, speed and scale of migration, mostly into urban spaces. Boggacini (2015) argues that a key feature of superdiversity is the relevance of an 'emic' perspective, or, how 'social actors perceive, make sense of and react to the situated intersection between multiple attributes over their life course' (p. 611). This focus has led researchers to become interested in how different migrant groups 'act' in the countries and contexts in which they live and how they make sense of their experiences. Generally, superdiversity has been a mainly European concern, with researchers such as Blommaert (2013) and Creese and Blackledge (2010), examining European urban spaces. The researchers have generally been indigenous or at least enculturated into the urban spaces they research and the research has involved the lead (European) researchers in field work and analysis. I would like to argue that research in superdiversity be conceptually expanded to any cross-cultural research where the focus is on gaining an emic view. In this perspective, the focus need not be European but can be on any place where migration has had an effect, the space can be rural as well as urban and the researchers can be local as well as international. This is not to say that these contexts have been consciously excluded from studies of superdiversity but rather that they have not attracted attention in quite the same way.

The case studies discussed here represent both conceptualisations. The first describes the ethically important moments experienced by an indigenous researcher working on a European funded project in a developing country. There are a number of levels of superdiversity in this case. First, the project focused on worker migration in a developing country. Second, the research was instigated by a European team and funded by European money. Third, recognising that the emic perspective they were seeking would not be uncovered if they carried out the field work themselves, the team employed researchers from the country they were researching. These researchers were indigenous but were educated urbanites who had no link with the community they researched, adding a further level of cross-cultural lamination. Fourth, the research was carried out in a remote, rural area. 
The second study is more recognisably 'superdiverse'. The study took place in a large Northern European city and centred on two cases. The first was a Polish migrant running a small business - a local shop. The second was a self-employed Polish migrant who was involved in theatre and the arts. The research team was lead by a European, indigenous to the country, and research funds came from a European research council. The research team employed a (native) Polish bilingual researcher to carry out most of the field work in order to get an emic view. In addition to fieldworker, there were two 'lead' researchers who were part of the successful team that bid for the project money. They were both from Asia.

Although very different, the two projects shared many features: the focus of both research projects was migrant workers; the research projects were led by European academics; the fieldworkers were hired by these European academics who had won funding from European funders for their projects; and the field researchers both spoke the language of those they were researching but did not fully identify with the research participants.

I am grateful to both fieldworkers who spoke to me at length about their research and the ethical issues they faced. The vignettes presented below are constructed from the notes and recordings I took during our conversations.

\section{Ethically important moments in researching communication in superdiversity}

\section{Vignette 1 - Joel's story}

I was very pleased to get involved in the research project to investigate the experiences of migrant workers in my country. It is well-known that thousands of men and many women leave each year to work abroad in order to earn money to feed their families and send their children to school. Often they are gone for many months at a time but until this project, there had been little academic interest in their lives or the sacrifices they make.

My day job is a university lecturer but with a colleague I were employed on a contractual basis by a European university to carry out an interview study with the workers which focused on English use in the context of the global job market. The region selected for the research was miles from the capital city where I had been brought up and now work. The selection of region was made on the basis of the number of migrant workers. In a minor way I felt like a migrant worker myself as I had to spend weeks in the village, carrying out interviews. Village life was very different to what I was used to and it wasn't always easy to live in a local way with the informants. I often felt like an outsider. 
During the study, we encountered a number of ethical issues that we had to address in the field. Some of these emerged as we were negotiating access to the participants, which was done through gaining the trust of the village elders. Early on, they were suspicious of our motives. Perceiving us as wealthy, and perhaps even as donors, they requested gifts, which we worried could be misconstrued as 'payment' for information by our employers. The request for gifts marked a serious concern of the villagers. They wanted to know what was in the research for them. One said to me, 'you are going to get promotion and we'll be left here'. They had encountered research teams before who had come to the village, elicited information and then left again with no benefit being gained by the villagers. They had begun to realise that their stories were of some value and did not wish to give them away cheaply, particularly when no larger benefit from the research was discernable. We decided after discussion that food gifts would be acceptable both to the villagers and the European employers and we provided sweetmeats, which was a locally meaningful token.

Gaining consent was also an issue in terms of the European University's ethics procedure. Throughout, the villagers were far less concerned with ethical procedures than we were yet we felt we had to play it safe, as we were accountable to a western group of researchers. Consent forms were provided but many of those we talked to could not read or write. Furthermore, signing one's name or getting a thumb print from those who couldn't write in this context was a very important act, and usually denoted some binding legal action. In the past, villagers had been caught out, authorising a document they couldn't read only to find later that they had signed away rights and land. In the end, we decided to gain oral consent. Like providing food gifts, we made this decision ourselves - it was impossible to contact the project leaders from the field for their approval.

We wanted to talk to the women who had been left behind as well as the male migrant workers. This was difficult. Both researchers were male and so could not talk to a female without the presence of a male from the woman's family. This was arranged but what usually happened was that the male family member would answer the questions on behalf of the woman. It was never clear to us whether the woman shared the views articulated by the men or not.

Throughout the project power loomed large. To gain access, we had to approach the village elders, who were the powerful people in the village. Our power as academics was made visible in these discussions (and when we later visited participants) as we were always offered chairs while the villagers sat on the floor. We recorded the interviews; this was not contested by 
villagers, not because they were all comfortable being recorded but because they didn't have the means to challenge us. When a western member of the research team came to spend time in the field with us, he was welcomed, probably because he could speak some of the language and displayed intercultural skills such as eating the local food and greeting people appropriately. The villagers wanted to talk to him and not to us and they over-performed for him, speaking in ways that we had not seen before.

Another power issue emerged when the data collection came to an end. My colleague and I are both academics working in the higher education sector. We saw this research project as a way to develop our academic profiles. However, in the field, we felt practically empowered (as we were doing the data collection) but intellectually disempowered (as our western colleagues were doing the thinking work). This dichotomy of roles remained for some time. When it came to producing written outputs such as the project report and journal articles, we were not included or even asked to contribute. It was only after demonstrating that we could write up research effectively that we were invited to jointly author papers.

\section{Discussion}

This brief vignette throws up a number of issues with respect to the discussion of ethics above. In terms of the medical principles first introduced, two are of particular interest: informed consent and beneficence. The common western practice of signing a consent form was not appropriate as signing in this context has negative historical associations. However, signed consent forms are very much a part of the macro ethical practices of most (western) universities and often a requirement of gaining ethical permission from ethical review boards. There was therefore a tension between institutional requirements and 'virtue ethics' and 'the ethics of care': in this case, Joel and his research partner recognised that an ethical decision was necessary and chose to respond positively to the context, waiving the requirement to sign as long as the informants indicated they understood the focus of the research. Of course it will have been the responsibility of the European research team to agree this approach with the ethics committee but there are precedents for the decision Joel took. Agar, an extremely well- 
known and regarded American ethnographer, argues in The Professional Stranger (2008) that oral consent is as valid as written consent, particularly when research subjects are vulnerable (he worked with drug users in America). While Joel's subjects are not vulnerable in the same sense, the circumstances of researching in a superdiverse context also require a sympathetic and considered response, which Joel provided.

Beneficence requires that researchers should ensure that the research is in the interests of the participants. The European research team would doubtless argue that the research project would result in better understanding of the migrant workers' motivations for learning English and perhaps even to changes in English language teaching in the area. However, for the participants, there is no discernable benefit to them from the research in the short term. In this context, gift-giving is a reasonable response to local expectations, particularly since donors have set the expectation that gifts are expected from (wealthy) visitors to the village.

Let us turn now to the issue of interviewing women in this context. Although Joel and his research partner were able to access the women, it was only in the presence of a male family member. This constraint would have had an effect on any data generated in the interview as in essence it becomes a co-construction between three people rather than two, even if the male had remained silent (see Garton and Copland, 2010, for a discussion of co-construction). However, the male did not remain silent: as Joel reported to me, 'we asked the women questions but the men answered for them'. This was another ethically important moment for Joel and his research partner. They wanted to hear the women's voices but local practices denied women a voice in this kind of public arena. They decided in the interests of the ethics of care to continue with the interviews and not to insist that the women speak for themselves. When they reported the issue to the European team, money was found to employ a female researcher. 
Finally we come to the ethical issues around power. In the village, power shifted between researchers and participants: researchers could not gain access without the elders' permission yet villagers were not able to context the recording of interviews as they lacked the academic literacy required to object. When the western researcher arrived, Joel and his co-researcher found their status dropped as the villagers preferred to talk to the person they considered to be in charge, despite his not having spent time in the village building relationships and understanding local norms. These examples demonstrate the contingent and locally contextual nature of ethical issues. In each case, Joel had to consider how the virtue of care could be most effectively be evoked. He also had to negotiate his own researcher positionality with respect to behaving ethically, in one context acquiescing to village elders' requests; in another, pushing ahead with the recordings despite villagers' misgivings.

Ethical issues are also in play in research teams where there are powerful and less powerful actors. The ethical principle of justice (that everyone is treated fairly and equally) is of particular relevance. As Creese (2015) notes:

There are ethical issues too in the employment, development, and mentoring of researchers in the team. Factors at play in this dynamic include the relative employment status, gender, ethnicity, and age of members of the research team.... There are always structural hierarchies, some of which are institutionalised, such as in employment contracts or professional status, while others are less institutionalised, but still pernicious, embedded in discourses of 'reputation' and 'fame'. (p.66)

These issues became very real for Joel and his colleague once the European research team began work on publications. As academics in their own right, they felt that they should have been allowed to contribute to writing the report and journal articles. At first, this was denied them: their contracts did not stipulate that they would be involved in publications and the 
European research team, focused as they would have been on publishing as much as possible in as short a time frame as possible, may not have even considered their contributions could have been valuable. However, as Creese (2015) argues, 'consideration of ethical behaviour - in terms of exploitation and vulnerability - therefore extends beyond the research site and the research participants to somewhere much closer to home' (p.66), that is, the research team. Eventually, Joel and his colleague were invited to contribute, demonstrating that the European team was also able to exercise virtue ethics.

Vignette 2 - Amelia's story

Although I am originally from Poland, I have lived here for a long time. I studied here and I have worked here. My friends are mostly local although some are from further afield. I never speak Polish, unless I call home. Technically Polish is my own language but something about it isn't mine anymore. I would call myself an academic - I have worked as a researcher and in universities over the last few years.

Of course, being Polish was really important in securing my role as a field worker on a recent project. The European research team wanted to explore migrants and the language of workplaces and given their large numbers Polish migrants were selected. I spent time with two Polish workers. The first was the owner of a small Polish shop. The customers were therefore mostly Polish although migrants from places such as Hungary and Slovakia also shopped there. I spent many days conducting an ethnographic study in the shop, sitting around, watching people as they interacted with my key participant and chatting to her about all sorts of things when business was quiet. At the end of each day I would write up my field notes for later analysis.

The second Polish migrant worker was very different. She was involved in the arts and theatre and led quite an exciting life, working on different projects and meeting artistic people. 
Although she rented a flat with people from different ethnic and cultural backgrounds, she kept in touch with Polish people and Polish affairs. Again I conducted an ethnographic study. I spent time at her flat but I also followed her around as she went to meetings or worked on projects.

There were a number of ethically important moments during my time on the research project. For example, I spent many days in the shop. In quiet periods, I chatted for hours on end with the owner, usually about the small things in life. She was amazed that I didn't watch Polish television (I prefer local TV) or keep up with current affairs in Poland. Nevertheless, we still managed to find lots in common. She enjoyed talking to me, she confided in me and she trusted me with all kinds of secrets, including some dishonest trading activities. The owner came to regard me as an important friend, someone who kept her going on a day-to-day basis and who supported her.

To be honest, I wasn't expecting to develop this kind of relationship with the owner. When the ethnographic study came to an end, I had to find a way to extricate myself. This was very hard indeed. The owner really didn't want to see me go and I started to worry about her mental health when she no longer had a friend to talk to everyday (I had realised during our talks that she suffered from some mental health issues that were not apparent to the research team or to me at first). On the other hand, I couldn't keep going back to the shop: I liked the owner but I didn't regard her in the same way as she regarded me.

Another interesting ethical issue had arisen earlier in the ethnography. The European research team had decided to invite all the participants on the project to one of the universities to discuss the project, to thank the participants and to explain aspects of the research such as ethical procedures. The owner of the shop dutifully turned up to this event but was clearly very uncomfortable. She had not been to university and seemed to find the institution daunting. 
She also could not understand why such a lot of time and energy was being devoted to ethical issues, which to her seemed a waste of time. She kept saying that it was all common sense and couldn't understand why the researchers kept on about it. It was clear she could not wait to leave.

I suppose the strangest day I spent in the shop was when the project leaders joined me there for a day. The shop was actually very small and my presence already seemed to take up a lot of space, no matter how hard I tried to be unobtrusive. The shop was also populated by Eastern Europeans, although now and again a British customer would come in to buy something. You can imagine how the dynamic changed when the two project leaders arrived, not least because they were both Asian. Not only did the three of us take up lots of room, the leaders were extremely conspicuous and drew comments from many of the customers who were suspicious of them. Nobody behaved that day in a natural way; everyone (including the researchers) found it quite a disquieting experience.

The final ethically important moment I will share involved the second participant. I found I had much more in common with this Polish national. Like me, she had lived locally for many years and rather than living in a Polish community, she had international friends and colleagues. She was interested in many of the same things as me and we discussed national politics, local cultural events and so on. She was delighted to be part of a serious research project; she saw it as a validation of her identity as a strong Polish woman who played an important role in society. She also liked the fact that we shared two languages and used these linguistic resources in different work situations, for example, sometimes speaking Polish in front of a co-worker who could only speak English, in order, I think, to exclude him from the conversation. 
However, as I came to know this participant, I also realised that she too suffered from mental health problems. These would manifest themselves in rants and rages, which I got used to but did not enjoy witnessing. The most dramatic of these happened on the day one of the project leaders was with us for the day. The project leader was extremely shaken by the outburst as it was the first time he had witnessed such behaviour from a participant. Although I really liked the participant and enjoyed working with her, the severity of her rage made me question whether her involvement in the research was putting her under undue stress. The project leader was of the opinion that she should be counselled off the project. However, although I gave her this choice, I felt abandoning her at this point would contribute to her fragile state of mind. To me, we had a responsibility to support her, to accept her and to make her feel included. So, in the end she continued to work with us.

\section{Discussion}

The first ethically important moment that Amelia identifies is exiting the field. This is an area that has received some attention over the years from ethnographers have recognised this a difficult and ethically important action (e.g. Coffey 1999). Exiting the field can be tied up, as in Amelia's case, with the development of a personal relationship with the researched. A sense of betrayal is one often felt by research participants on reading research reports (see, for example, Scheper-Hughes 2000) and the researcher must consider how to deal with rejection. Amelia's case is slightly different in that publication has not (yet) caused upset. Rather there is an imbalance in affection: the informant does not want to lose a friend whereas Amelia is less concerned about losing contact with the informant. In terms of the ethical principles discussed above, the researcher, therefore, must also consider non-maleficence, that is, do no harm. If a research participant is upset by what is published, is this doing harm? If a researcher breaks up a 'friendship' however tentative this might be, is this doing harm? 
As a number of researchers have pointed out (e.g. Kubanyiova 2008; Copland 2015), there is a tension between the 'do no harm' principle and the importance of producing research products, often characterised as 'doing the greater good'. In most cases, because of pressures to complete projects, to publish research, to meet institutional requirements such as completing reports, 'doing the greater good' wins the ethical argument. However, the end of the project described here meant the end of a friendship. Furthermore, in this superdiverse context, where the participant was a migrant worker who had welcomed a fellow national into her shop and shared her secrets, the friendship had an enhanced value and the participant felt bereft when it was curtailed. Harm was done to the participant when Amelia left, but to what extent should Amelia feel responsible for this harm? Should the European research team have planned for this eventuality?

The next ethical issue involves the visit of the shop owner to the university to take part in an information event about the research project. The organisers of the event probably had in mind the principles of beneficence and justice in organising the event in that they wanted to ensure that research was not 'on' participants but 'with' participants and that everyone involved was treated fairly and equally. However, the event had a negative effect on the owner, who seemed to feel out of her depth and alienated by the experience. In addition, the effort that the research team was putting into behaving ethically manifested itself as a waste of time in the owner's eyes, an accusation that should be taken seriously given that for this business-owning participant, time was precious.

This situation demonstrates the importance of developing an emic perspective in issues of ethics. The research team seemed to be 'doing ethics' from an etic perspective, interpreting for the participants what would be important ethically. In contrast, this participant rejected intellectualised notions of ethical behaviour, consistently rejecting the underlying notion that she had anything to hide. The research team's ethics of care was not in this case successful. 
The appearance by the two senior Asian researchers in the very small shop for an extended period also posed ethical issues. The customers viewed the visitors with suspicion because of their ethnic identity. There are issues of racism in play here, which were not confronted or discussed. Moreover, natural communication in the shop was curtailed because of the senior researchers' visit, providing a classic example of the observer's paradox.

The final ethical issue from this vignette draws on the principles of informed consent and nonmalefience to discuss the second participant's seemingly high levels of stress manifested in angry outbursts. The participant had demonstrated to Amelia that she was very happy to be involved in the research as she saw it as identify affirmation. However, the outbursts that Amelia observed on a number of occasions (and which came to a head on the day the senior researcher joined the ethnography) became an ethically important moment for her and as she realised the situation required an ethical response (virtue ethics). Her decision was to discuss the incident with the participant but not to counsel her off the project, which the senior researcher felt might be in the participant's best interests. Instead, Amelia believed she had a duty of care to the participant whose self-esteem she thought would be damaged if she were asked to withdraw.

\section{SUMMARY}

A number of the issues explored in the above section could arise in research projects in homogenous, diverse and superdiverse settings. In this section, I will focus on the issues that have a particular resonance for researching communication in superdiversity.

First, let us turn to researching migrants. Both projects discussed here took a practical approach to researching migrant experiences by employing field workers who could speak the language of the researched and shared some cultural understandings. However, this decision created a particular set of ethical dilemmas for the field workers. First, the habitus (Bourdieu 
198467589) of the researchers was very different to that of the researched: Joel was an urban academic sent to research the rural working class who migrated from necessity; Amelia had naturalised to a great extent and shared the interests and values of friends in her adopted country rather than those of friends she had left behind and characterised by the shop owner. Sharing the language and some cultural understandings certainly supported the researchers with access to the researched: however, these affordances were offset by demands made of them by the researched in the field which challenged them to consider whether their actions were ethical and to what extent.

In addition to the demands made by participants, Joel and Amelia also had to mediate between the understandings and expectations of the European research teams and the norms and expectations of the participants who came from very different traditions, which also threw up ethical dilemmas. Joel, for example, was expected to collect signed consent forms from participants in order to satisfy the macro ethics of the employing institution. Amelia was required to persuade the informant to spend a day in an alien context, which was clearly of no interest to the participant and in fact made her extremely uncomfortable.

Finally, both Joel and Amelia had to contend with institutional expectations which arose because of their status as field workers researching migrants (rather then as project leaders). In Joel's case, he had to persuade the employing institution of his academic credentials so that he could be included as a co-writer on research products. In Amelia's, her concern over her second research participant's health meant she rejected the advice from senior colleagues to withdraw the participant and instead continued to work with her in order to provide emotional support.

Both Joel and Amelia encountered ethically important moments in their research. As can be seen from this discussion, both arrived at independent decisions about how to respond based on 
virtue ethics and ethics of care. Nonetheless, their decisions were not all either easily made or easy to live with. Their willingness to discuss their decisions demonstrates their willingness to interrogate their ethical decision making processes long after a leaving the field and to be open to alternative interpretations and responses. To me, this is the hallmark of ethically informed and ethically aware researchers.

Researching communication in superdiversity will never be free from ethical issues. However, given the complexity of the human relationships that are necessarily involved, it will also continue to be difficult to predict the ethical dilemmas when projects are being designed. Although ethical approval committees should be able to offer support and advice at planning stages, researchers in the field and in those in the greater research team will need to develop virtue ethics and ethics of care to deal sensitively and humanely with these dilemmas as they arise. The growth in research in superdiversity, which is paralleled by an increase in research papers that detail ethical processes and decisions, means that experiences are being shared and some expertise in dealing with issue is being developed. However, it is important that we listen to the experiences of those working in the field as well as those writing up the research if we are to develop sensitivity to ethically important moments that we can respond to drawing on both virtue ethics and the ethics of care.

\section{FURTHER READING}

Copland, F. and Creese, A. (2015). Ethical issues in linguistic ethnography: Balancing the micro and the macro. In De Costa, P. I. (Ed.) Ethics in applied linguistics research: Language researcher narratives. New York: Routledge.

Guillemin, M. and Gillam, L. (2004). Ethics, Reflexivity, and "Ethically Important Moments" in Research. Qualitative Inquiry, 10/2, pp. 261-280 
Kubanyiova, M. (2008) Rethinking research ethics in contemporary applied linguistics: the tension between macroethical and microethical perspectives in situated research. Modern Language Journal, 92/4, pp. $503-18$

Scheper-Hughes, N. (2000) Ire in Ireland. Ethnography, 1/1, pp. 117- 140

\section{References}

Agar, M. (2008). The Professional Stranger(2nd edition). Bingley: Emerald Group Publishing

Blommaert, J. (2013) Ethnography, Superdiversity and Linguistic Landscapes: Chronicles of Complexity. London: Multilingual Matters

Boccagni, P. (2015) (Super)diversity and the migration-social work nexus: a new lens on the field of access and inclusion?, Ethnic and Racial Studies, 38:4, 608-620, DOI:

$10.1080 / 01419870.2015 .980291$

Bourdieu, P. (1984). Distinction: A Social Critique of the Judgement of Taste. London, Routledge

Coffey, A. (1999) The ethnographic self: fieldwork and the representation of identity. London: Sage

Copland, F. (2015) Case study two: researching feedback in pre-service teacher education'. In Copland, F. and Creese, A. with Rock, F. and Shaw, F. Linguistic ethnography: collecting, analysing and presenting data. London: Sage pp. 89 - 116

Copland, F. and Creese, A. (2015). Ethical issues in linguistic ethnography: Balancing the micro and the macro. In De Costa, P. I. (Ed.) Ethics in applied linguistics research: Language researcher narratives. New York: Routledge. Pp waiting for book to arrive!!

Creese, A. (2015) Case study one: reflexivity, voice and representation in linguistic ethnography. In Copland, F. and Creese, A. with Rock, F. and Shaw, F. Linguistic ethnography: collecting, analysing and presenting data. London: Sage pp. 61 - 88

Creese, A. and Blackledge, A. (2010) Towards a sociolinguistics of superdiversity. Zeitschrift für Erziehungswissenschaft 13:549-572.

Davies, C.A. (2008) (2 $2^{\text {nd }}$ edition) Reflexive ethnography: a guide to researching selves and others. London: Routledge

Garton, S. and Copland, F. (2010) 'I like this interview: I get cakes and cats!' The effects of prior relationships on interview talk. Qualitative Research 10/5, pp. 533 - 551 
Guillemin, M. and Gillam, L. (2004). Ethics, Reflexivity, and "Ethically Important Moments" in Research. Qualitative Inquiry, 10/2, pp. 261-280

Humphreys, L. (1970) Tearoom trade: Impersonal sex in public places. Chicago: Aldine Publishing Company

Kubanyiova, M. (2008) Rethinking research ethics in contemporary applied linguistics: the tension between macroethical and microethical perspectives in situated research. Modern Language Journal, 92/4, pp. 503 -18

LeCompte, Margaret D. and Goetz, Judith Preissle (1982) 'Problems of Reliability and Validity in Ethnographic Research', Review of Educational Research 52(1): 31-60.

Rose, G. (2013) Visual Methodologies ( ${ }^{\text {rd }}$ edition). London: Sage

Scheper-Hughes, N. (1976) Saints, Scholars and Schizophrenics. Oakland: California

Scheper-Hughes, N. (2000) Ire in Ireland. Ethnography, 1/1, pp. 117- 140

Vainio, A. (2012) Beyond research ethics: anonymity as 'ontology', 'analysis' and 'independence'. Qualitative Research 13/6, pp. 685-698

Wiles, R., Prosser, J., Bagnoli, A., Clark, A., Davies, K., Holland, S, Renold, E. (2008)

Visual Ethics: Ethical Issues in Visual Research. ESRC National Centre for Research Methods Review Paper http://eprints.ncrm.ac.uk/421/1/MethodsReviewPaperNCRM-011.pdf (accessed, October 30th, 2015) 
